\title{
Matrix Metalloproteinase-2 -1306 C>T Gene Polymorphism is Associated with Reduced Risk of Cancer: a Meta-analysis
}

\author{
Shafiul Haque ${ }^{1,2}$, Naseem Akhter ${ }^{2}$, Mohtashim Lohani $^{3}$,Arif Ali ${ }^{2}$, Raju K Mandal $^{1 *}$
}

\begin{abstract}
Matrix metalloproteinase-2 (MMP2) is an endopeptidase, mainly responsible for degradation of extracellular matrix components, which plays an important role in cancer disease. A single nucleotide polymorphism (SNP) at -1306 disrupts a Sp1-type promoter site. The results from the published studies on the association between MMP2 -1306 C>T polymorphism and cancer risk are contradictory and inconclusive. In the present study, a meta-analysis was therefore performed to evaluate the strength of any association between the MMP2 -1306 $\mathrm{C}>\mathrm{T}$ polymorphism and risk of cancer. We searched all eligible studies published on association between MMP2 -1306 C $>$ T polymorphism and cancer risk in PubMed (Medline), EMBASE and Google Scholar online web databases until December 2013. Genotype distribution data were collected to calculate the pooled odds ratios (ORs) and 95\% confidence intervals ( $95 \%$ CIs) to examine the strength of the association. A total of 8,590 cancer cases and 9,601 controls were included from twenty nine eligible case control studies. Overall pooled analysis suggested significantly reduced risk associated with heterozygous genotype $(\mathrm{CT}$ vs $\mathrm{CC}: \mathrm{OR}=0.758,95 \% \mathrm{CI}=0.637$ to $0.902, p=0.002)$ and dominant model $(T T+C T$ vs $C C: O R=0.816,95 \% \mathrm{CI}=0.678$ to $0.982, p=0.032)$ genetic models. However, allelic ( $T$ vs $\mathrm{C}$ : $\mathrm{OR}=0.882,95 \% \mathrm{CI}=0.738$ to $1.055, \mathrm{p}=0.169)$, homozygous (TT vs $\mathrm{CC}$ : $\mathrm{OR}=1.185$, 95\% $\mathrm{CI}=0.825$ to $1.700, \mathrm{p}=0.358$ ) and recessive (TT vs $\mathrm{CC}+\mathrm{CT}$ : $\mathrm{OR}=1.268,95 \% \mathrm{CI}=0.897$ to $1.793, \mathrm{p}=0.179$ ) models did not show any risk. No evidence of publication bias was detected during the analysis. The results of present meta-analysis suggest that the MMP2 -1306 C $>\mathrm{T}$ polymorphism is significantly associated with reduced risk of cancer. However, further studies with consideration of different populations will be required to evaluate this relationship in more detail.
\end{abstract}

Keywords: Meta-analysis - MMP2 - cancer - susceptibility - polymorphism

Asian Pac J Cancer Prev, 16 (3), 889-896

\section{Introduction}

Cancer is a dreadful disease and shown major impact on human health associated with high morbidity and mortality worldwide (Jemal et al., 2011). It is now established that cancer is a multistep process, which results from complex interactions between environmental and genetic factors (Pharoah et al., 2000). Its increasing incidence and mortality rate during the last two decades posed a big challenge to clinicians and scientists. The precise etiology of this fatal disease is still unclear, it has been suggested that low penetrance gene interplay with environmental factors is a major cause of increasing risk of cancer (Lichtenstein et al., 2000). Thus, it is anticipated that the detection of host genetic factors for susceptibility to cancer would significantly help the therapeutic strategies and global control of this deadly disease.

Matrix metalloproteinase (MMPs) are a superfamily of zinc-dependent endopeptidases, which are involved in degradation of extracellular matrix and basement membrane, required for tumor cell migration and dissemination (Wagenaar et al., 2004; Curran and Murray, 1999). MMPs also contribute to epithelial-mesenchymal transition, angiogenesis, autophagy, and apoptosis and mainly produced by infiltrating inflammatory cells and stromal cells, which can be stimulated by molecules on the surface of cancer cells (Nabeshima et al., 2002; Deryugina and Quigley, 2006).

MMP2 (gelatinase A, localized on 16q13) is a member of the MMP family that primarily hydrolyzes type IV collagen and known to play a key role in tumor invasion and metastasis (Bjorklund and Koivunen, 2005). On the other hand, MMP2 is also involved in growth factorbinding proteins and receptors, which are main factors for cell proliferation and inhibition of apoptosis (Sternlicht and Werb, 1999). The higher expression of MMP2

${ }^{1}$ Research \& Scientific Studies Unit, College of Nursing and Allied Health Sciences, Jazan University, Jazan, Saudi Arabia, ${ }^{2}$ Department of Biosciences, Jamia Millia Islamia (A Central University), New Delhi, ${ }^{3}$ Department of Biotechnology, Integral University, Lucknow, India*For correspondence: rkmandal@live.com 
protein or mRNA has been observed in several human cancers (Bonomi, 2002; Lebeau et al., 2004). Functional SNPs in MMP2 gene's promoter regions may modify the production of proteolytic enzymes, and in turn modify the risk for carcinogenesis. At the genetic level, many single nucleotide polymorphisms (SNPs) have been identified throughout the coding and non-coding regions. $\mathrm{A} \mathrm{C} \rightarrow \mathrm{T}$ (rs243865) transition which is found in promoter region -1306 reported to abolish the Sp1 transcriptional factor binding site (CCACC box) and display lower promoter activity and reduction in transcriptional activity of MMP2 gene (Price et al., 2001). Sp1 is a ubiquitously expressed transcription factor that binds to GC/GT-rich elements to regulate a variety of genes. The CCACC box has been shown to be essential for Sp1 binding and promoter function in several genes by invariably activating transcription (Kang et al., 1996; Qin et al., 1999).

Numbers of molecular epidemiological case-control studies have been carried out to interpret the possible association between the MMP2 -1306 C > T polymorphism and human malignancy in different populations $(\mathrm{Xu}$ et al., 1999; Yu et al., 2002; 2004; Miao et al., 2003; Li et al., 2004; Zhou et al., 2004; 2005; Elander et al., 2006; Kader et al., 2006; O-Charoenrat and Khanatapura, 2006; Hettiaratchi et al., 2007; Roehe et al., 2007; Rollin et al., 2007; Lei et al., 2007; Zhai et al., 2007; Baltazar et al., 2008; Delgado et al., 2008; Dos et al., 2009; Ohtani et al., 2009; Li et al., 2010; Aysegul et al., 2011; Chaudhary et al., 2011; Kumar et al., 2011; Satpute et al., 2012; Saeed et al., 2013; Srivastava et al., 2013a; 2013b; Wieczorek et al., 2013; Yaykasli et al., 2013; Shalaby, et al., 2014), but results are always inconsistent. Inconsistency in results could be attributed to small sample size and low statistical power. Recently, Burton et al. (2009) suggested that large enough sample size is good to study the genetic associations with complex disease. Therefore these results prompted us to perform the meta-analysis from pooled all published studies to determine the more precise association and understanding the role of MMP2 $-1306 \mathrm{C}>\mathrm{T}$ polymorphism in cancer. Meta-analysis is a powerful tool because it employs quantitative method to combine the data from individual studies where individual sample sizes are smaller and have lower statistical power, and provides robust conclusion (Cohn and Becker, 2003; Mandal et al., 2013).

\section{Materials and Methods}

\section{Identification and evaluation of pertinent studies}

We searched electronic research literature from PubMed (Medline) and EMBASE, last search updated on December 2013 with the combination of following keywords: 'MMP2 promoter (polymorphism OR mutation OR variant) AND cancer susceptibility. The search was focused on studies that had been conducted in humans. All retrieved articles were evaluated by reading the titles and abstracts, and all published studies matching with the eligible criteria were retrieved for this meta-analysis. We also did manual search of reference lists from the retrieved articles for other eligible articles.

\section{Inclusion and exclusion criteria}

Articles included in the current meta-analysis had to meet all the following criteria: a) must evaluated the association between MMP2 polymorphism and cancer risk, b) used a case-control design, c) recruited histologically confirmed cancer patients and healthy controls, d) have available all genotype frequency in case and control, e) published in the English language. In addition to above, when the same patient populations appeared in several publications, only the most recent or complete study was included in this meta-analysis. The major reasons for study exclusion were, overlapping of the data, case-only studies, review articles, and genotype frequencies or number not reported. The selection procedure of most pertinent studies has been depicted as a flow diagram in Figure 1.

\section{Data extraction and quality assessment of the studies}

For each retrieved publication, the methodological quality assessment and data extraction were independently abstracted in duplicate by two independent investigators using a standard protocol. Data-collection form was used to ensure the accuracy of the collected data by strictly following the inclusion criteria mentioned above. The major characteristic abstracted from the retrieved studies included the name of the first author, year of publication year, the country of origin, the number of cases and controls, type of cancer, genotype frequencies for cases and controls and source of genotyping. Cases related with disagreement on any item of the data from the collected studies were fully discussed with investigators to reach a final consensus.

\section{Statistical analysis}

In order to estimate the strength of association between MMP2 -1306 C>T polymorphism and cancer risk was measured by pooled ORs and their corresponding 95\%CIs were calculated (Woolf, 1995). Heterogeneity assumption between studies across the eligible comparison was performed by the chi-square-based Q-test (Wu and $\mathrm{Li}, 1999$ ). Heterogeneity was considered significant at p-value $<0.05$ to avoid underestimation of the presence

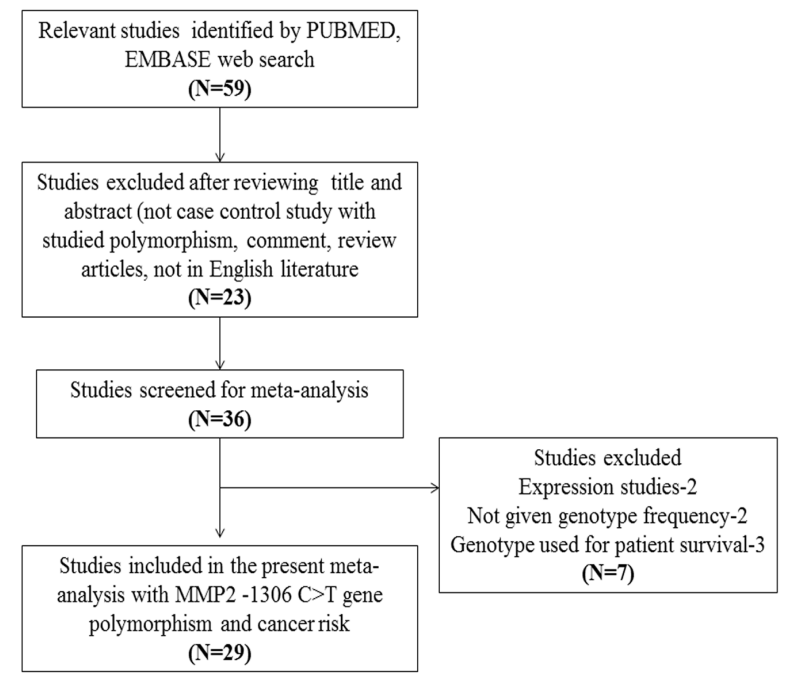

Figure 1. Flow Chart Showing the Identification and Selection of the Studies for thePresent Meta-analysis 
of heterogeneity. A fixed effect model (if $\mathrm{p}>0.05$ ) (Mantel and Haenszel, 1959) or a random effect model (if $\mathrm{p}<0.05$ ) (DerSimonian and Laird, 1986) was used for pooling the results. Furthermore, $\mathrm{I}^{2}$ statistics was also employed to efficiently test for the heterogeneity (Higgins et al., 2003). Hardy-Weinberg equilibrium (HWE) in the controls was measured via chi-square test. Funnel plot asymmetry was estimated by Egger's linear regression test which is a type of linear regression approach to measure the funnel plot asymmetry on the natural logarithm scale of the OR. The significance of the intercept was determined by the t-test ( $p$-value $<0.05$ was considered as representation of statistically significant publication bias) (Egger et al., 1997). All the statistical evaluations were performed by Comprehensive Meta-Analysis (CMA) Version 2 software program (Biostat, USA). All p-values were two sided and statistical significance was considered as p-value $<0.05$ for this meta-analysis.

\section{Results}

\section{Literature search and meta-analysis databases}

According to the selection (inclusion and exclusion) criteria, total twenty nine research articles were finally included through literature search from the PubMed (Medline), EMBASE and Google web search. All retrieved articles were examined carefully by reading the titles and abstracts, and the full texts for the potentially relevant publications were further checked for their suitability for this meta-analysis. Studies either showing MMP2 polymorphism to predict survival in cancer patients or considering MMP2 variants as an indicators for response to therapy were excluded straightaway. Similarly, studies investigating the levels of MMP2 mRNA or protein expression or relevant review articles were also excluded. We included only case-control or cohort design studies having frequency of all three genotype. Besides the database search, the references available in the retrieved articles were also checked for other potential articles (Table 1). Characteristic of included studies and distributions of genotypes, minor allele frequency (MAF) in the controls and cases have been shown in Tables 1 and 2.

\section{Publication bias}

The Begg's funnel plot and Egger's test were performed to evaluate the publication bias among the included studies for this meta-analysis. The appearance of the shape of funnel plots and the results of Egger's test have shown no evidence of publication bias in all the genetic models (Table 3 ).

\section{Evaluation of heterogeneity}

Q-test and $\mathrm{I}^{2}$ statistics were employed to test heterogeneity among the selected studies. Heterogeneity was observed in all the studied genetic models. Thus, random effects model was used to synthesize the data (Table 3).

Table 1. Main Characteristics of MMP2-1306 C>T Studies Included in the Meta-analysis

\begin{tabular}{|c|c|c|c|c|c|c|}
\hline First author and year & Cancer & Country & Study design & Genotyping method & Control & Cases \\
\hline Yaykasli et al. 2013 & Prostate & Turkey & HB & PCR-RFLP & 46 & 61 \\
\hline Saeed et al. 2013 & Colorectal & Saudi Arabia & HB & TaqMan & 122 & 95 \\
\hline Srivastava et al. 2013 & Bladder & India & HB & PCR-RFLP & 200 & 200 \\
\hline Wieczorek et al. 2013 & Bladder & Poland & HB & TaqMan & 199 & 241 \\
\hline Srivastava et al. 2012 & Prostate & India & $\mathrm{HB}$ & PCR-RFLP & 200 & 190 \\
\hline Satpute et al. 2012 & OSCC & India & HB & PCR-RFLP & 20 & 40 \\
\hline Chaudhary et al. 2011 & HNSCC & India & HB & PCR-RFLP & 422 & 426 \\
\hline Kumar et al. 2011 & Glioblastoma & India & $\mathrm{HB}$ & PCR-RFLP & 150 & 110 \\
\hline Aysegul et al. 2011 & Lung & Turkey & HB & PCR-RFLP & 100 & 200 \\
\hline Li et al. 2010 & ESCC, GCA & China & $\mathrm{HB}$ & PCR-RFLP & 624 & 592 \\
\hline Dos Reis et al. 2009 & Prostate & Brazil & $\mathrm{HB}$ & RT-PCR & 147 & 100 \\
\hline Ohtani et al. 2009 & Colorectal & Japan & HB & PCR-RFLP & 67 & 47 \\
\hline Delgado-Enciso et al. 2008 & Breast & Mexican & HB & PCR-RFLP & 90 & 90 \\
\hline Baltazar et al. 2008 & Cervical & Mexican & HB & PCR-RFLP & 126 & 54 \\
\hline Zhai et al. 2007 & HNCC & China & HB & Sequencing & 480 & 434 \\
\hline Lei et al. 2007 & Breast & Germany & PB & TaqMan & 952 & 959 \\
\hline Rollin et al. 2007 & NSCLC & France & HB & DHPLC & 90 & 90 \\
\hline Roehe et al. 2007 & Breast & Brazil & HB & DNA sequencing & 100 & 89 \\
\hline Hettiaratchi et al. 2007 & Colorectal & Australia & HB & RT-PCR & 471 & 503 \\
\hline Kader et al. 2006 & Bladder & USA & HB & TaqMan & 560 & 560 \\
\hline Ocharoenrat et al. 2006 & HNCC & Thailand & HB & ARMS-PCR & 250 & 239 \\
\hline Elander et al. 2006 & Colorectal & Sweden & HB & DHPLC & 208 & 127 \\
\hline Zhou et al. 2005 & Lung & China & $\mathrm{HB}$ & DHPLC & 777 & 770 \\
\hline Zhou et al. 2004 & Breast & China & HB & DHPLC & 509 & 462 \\
\hline Xu et al. 2004 & Colorectal & China & HB & DHPLC & 126 & 126 \\
\hline Yu et al. 2004 & Esophageal & China & $\mathrm{HB}$ & DHPLC & 777 & 527 \\
\hline Lin et al. 2004 & OSCC & China & $\mathrm{HB}$ & DHPLC & 147 & 121 \\
\hline Miao et al. 2003 & GCA & China & $\mathrm{HB}$ & DHPLC & 789 & 356 \\
\hline Yu et al. 2002 & Lung & China & $\mathrm{HB}$ & DHPLC & 852 & 781 \\
\hline
\end{tabular}


Shafiul Haque et al

Association of MMP2 -1306 C>T polymorphism and overall cancer susceptibility

We pooled all twenty nine studies together and it resulted into 8590 cancer cases and 9601 controls, examining the overall association between MMP2 -1306 $\mathrm{C}>\mathrm{T}$ polymorphism and cancer risk. The pooled OR from overall studies indicated reduced risk between MMP2 -1306 C>T polymorphism and cancer risk in

Table 2. Genotypic distribution of MMP2 -1306 C>T gene polymorphism included in the meta-analysis

\begin{tabular}{|c|c|c|c|c|c|c|c|c|c|}
\hline \multirow[t]{3}{*}{ Authors and year } & \multicolumn{4}{|c|}{ Controls } & \multicolumn{4}{|c|}{ Cancer cases } & \multirow{3}{*}{$\begin{array}{l}\text { HWE } \\
\text { p-value }\end{array}$} \\
\hline & \multicolumn{3}{|c|}{ Genotype } & \multirow{2}{*}{$\begin{array}{c}\text { Minor allele } \\
\text { MAF }\end{array}$} & \multicolumn{3}{|c|}{ Genotype } & \multirow{2}{*}{$\begin{array}{c}\text { Minor allele } \\
\text { MAF }\end{array}$} & \\
\hline & $\mathrm{CC}$ & CT & TT & & $\mathrm{CC}$ & CT & $\mathrm{TT}$ & & \\
\hline Yaykasli et al. 2013 & 42 & 4 & 0 & 0.04 & 51 & 7 & 3 & 0.10 & 0.75 \\
\hline Saeed et al. 2013 & 92 & 23 & 1 & 0.10 & 66 & 24 & 5 & 0.17 & 0.73 \\
\hline Srivastava et al. 2013 & 131 & 62 & 7 & 0.19 & 102 & 79 & 19 & 0.29 & 0.91 \\
\hline Wieczorek et al. 2013 & 120 & 72 & 7 & 0.21 & 143 & 85 & 13 & 0.23 & 0.33 \\
\hline Srivastava et al. 2012 & 131 & 62 & 7 & 0.19 & 101 & 78 & 11 & 0.26 & 0.91 \\
\hline Satpute et al. 2012 & 4 & 15 & 1 & 0.42 & 29 & 7 & 4 & 0.18 & 0.01 \\
\hline Chaudhary et al. 2011 & 298 & 104 & 20 & 0.17 & 299 & 87 & 40 & 0.19 & 0.007 \\
\hline Kumar et al. 2011 & 109 & 39 & 2 & 0.14 & 84 & 24 & 2 & 0.12 & 0.47 \\
\hline Aysegul et al. 2011 & 65 & 32 & 3 & 0.19 & 123 & 73 & 4 & 0.20 & 0.69 \\
\hline Li et al. 2010 & 487 & 137 & 6 & 0.11 & 491 & 94 & 80 & 0.19 & 0.28 \\
\hline Dos Reis et al. 2009 & 59 & 21 & 20 & 0.30 & 50 & 12 & 38 & 0.44 & $<0.0001$ \\
\hline Ohtani et al. 2009 & 64 & 3 & 0 & 0.02 & 41 & 5 & 1 & 0.07 & 0.85 \\
\hline Delgado et al. 2008 & 50 & 42 & 4 & 0.26 & 63 & 25 & 2 & 0.16 & 0.18 \\
\hline Baltazar et al. 2008 & 76 & 47 & 3 & 0.21 & 43 & 11 & 0 & 0.10 & 0.16 \\
\hline Zhai et al. 2007 & 402 & 70 & 1 & 0.07 & 358 & 66 & 3 & 0.08 & 0.25 \\
\hline Lei et al. 2007 & 520 & 359 & 69 & 0.26 & 520 & 359 & 70 & 0.26 & 0.51 \\
\hline Rollin et al. 2007 & 60 & 29 & 1 & 0.17 & 60 & 28 & 2 & 0.17 & 0.21 \\
\hline Roehe et al. 2007 & 66 & 32 & 2 & 0.18 & 63 & 21 & 5 & 0.17 & 0.4 \\
\hline Hettiaratchi et al. 2007 & 274 & 169 & 28 & 0.23 & 290 & 181 & 32 & 0.24 & 0.77 \\
\hline Ocharoenrat et al. 2006 & 190 & 56 & 4 & 0.12 & 206 & 33 & 0 & 0.06 & 0.95 \\
\hline Elander et al. 2006 & 109 & 89 & 10 & 0.26 & 69 & 49 & 9 & 0.26 & 0.12 \\
\hline Kader et al. 2006 & 312 & 202 & 31 & 0.24 & 297 & 218 & 28 & 0.25 & 0.82 \\
\hline Zhou et al. 2005 & 539 & 220 & 18 & 0.16 & 635 & 124 & 11 & 0.09 & 0.42 \\
\hline Zhou et al. 2004 & 349 & 154 & 6 & 0.16 & 381 & 79 & 2 & 0.08 & 0.01 \\
\hline $\mathrm{Xu}$ et al. 2004 & 92 & 32 & 2 & 0.14 & 106 & 19 & 1 & 0.08 & 0.67 \\
\hline Yu et al. 2004 & 539 & 220 & 18 & 0.16 & 409 & 112 & 6 & 0.11 & 0.42 \\
\hline Lin et al. 2004 & 107 & 34 & 6 & 0.15 & 101 & 20 & 0 & 0.08 & 0.13 \\
\hline Miao et al. 2003 & 542 & 229 & 18 & 0.16 & 312 & 44 & 0 & 0.06 & 0.27 \\
\hline Yu et al. 2002 & 585 & 248 & 19 & 0.16 & 644 & 127 & 10 & 0.09 & 0.21 \\
\hline
\end{tabular}

Table 3. Statistics to Test Publication Bias and Heterogeneity in the Present Meta-analysis

\begin{tabular}{|c|c|c|c|c|c|c|c|}
\hline \multirow[t]{2}{*}{ Comparisons } & \multicolumn{3}{|c|}{ Egger's regression analysis } & \multicolumn{3}{|c|}{ Heterogeneity analysis } & \multirow{2}{*}{$\begin{array}{l}\text { Model used for } \\
\text { the meta-analysis }\end{array}$} \\
\hline & Intercept & $95 \%$ Confidence Interval & p-value & Q-value & Pheterogeneity & $\mathrm{I}^{2}(\%)$ & \\
\hline $\mathrm{T} v s \mathrm{C}$ & -0.20 & $-2.75-2.34$ & 0.87 & 236.25 & $<0.0001$ & 88.14 & Random \\
\hline $\mathrm{TT}$ vs CC & -0.21 & $-1.47-0.92$ & 0.64 & 85.32 & $<0.0001$ & 67.18 & Random \\
\hline $\mathrm{CT}$ vs $\mathrm{CC}$ & -0.07 & $-2.12-1.97$ & 0.94 & 146.36 & $<0.0001$ & 80.87 & Random \\
\hline $\mathrm{TT}+\mathrm{CT} v s \mathrm{CC}$ & -0.05 & $-2.26-2.37$ & 0.95 & 186.05 & $<0.0001$ & 84.95 & Random \\
\hline $\mathrm{TT}$ vs $\mathrm{CC}+\mathrm{CT}$ & -0.12 & $-1.28-1.03$ & 0.82 & 80.14 & $<0.0001$ & 65.06 & Random \\
\hline
\end{tabular}
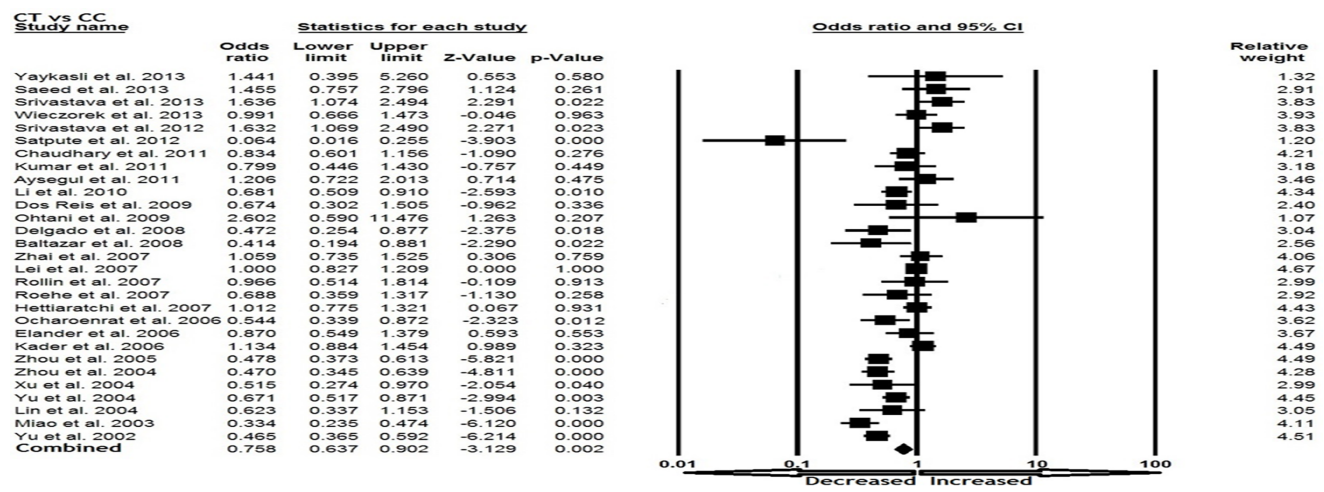

Figure 2. Forest Plot with ORs on Overall Cancer Risk Associated with MMP2 -1306 C>T Gene Polymorphism (CT vs CC; Heterozygous Model) 

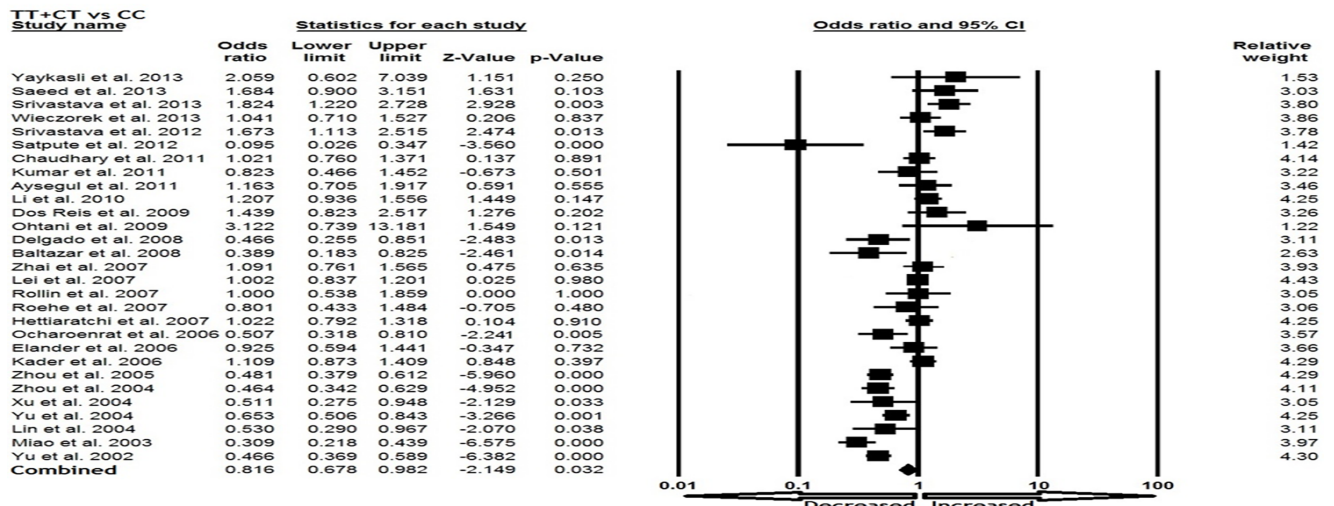

Figure 3. Forest Plot with ORs on Overall Cancer Risk Associated with MMP2 -1306 C>T Gene Polymorphism (TT+CT vs CC; Dominant Model)
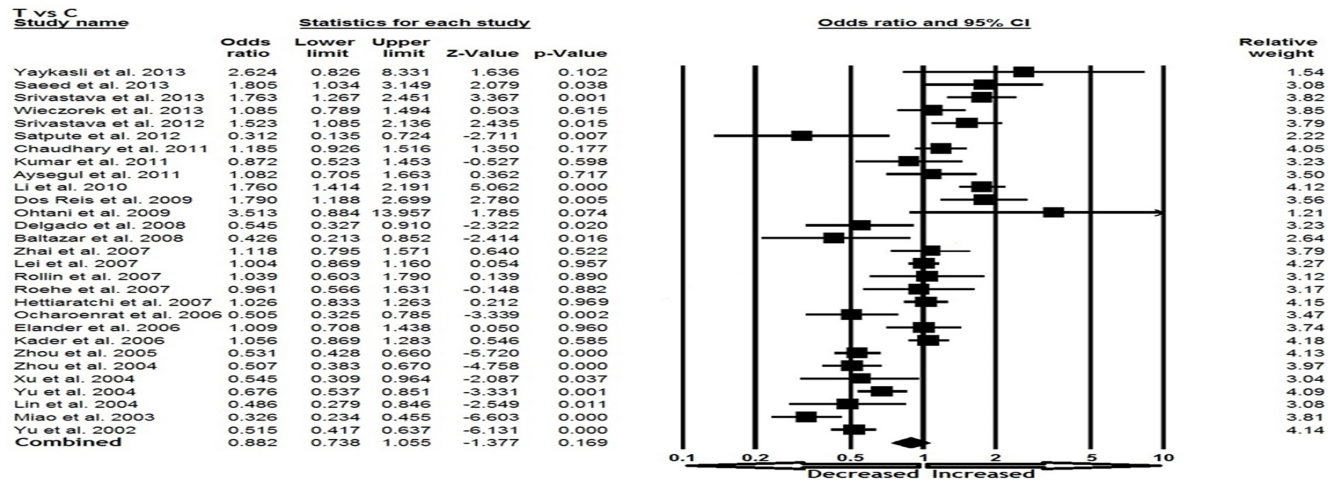

Figure 4. Forest Plot with ORs on Overall Cancer Risk Associated with MMP2 -1306 C>T Gene Polymorphism (T vs C; Allelic Model)
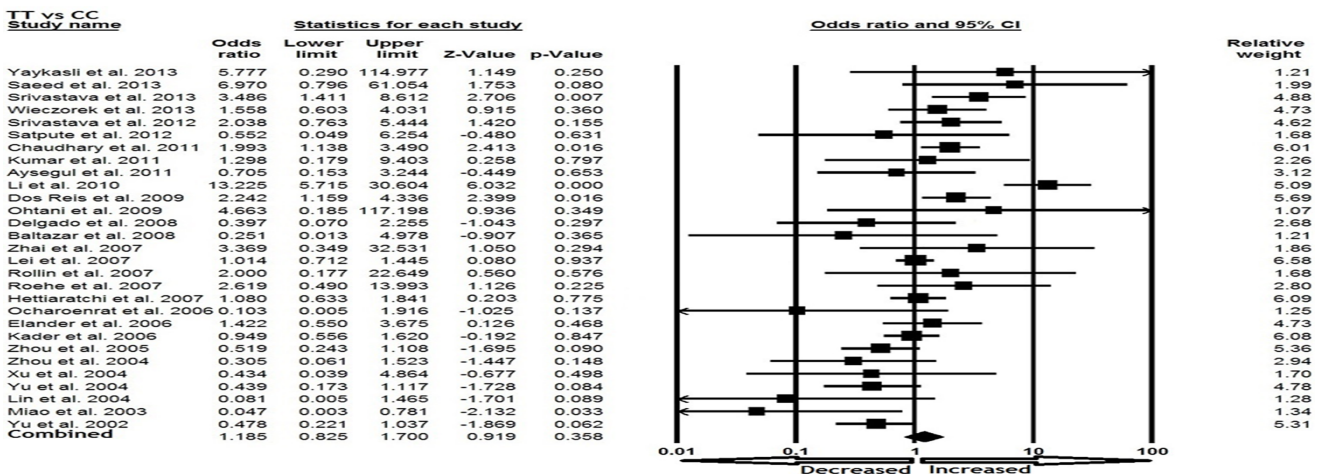

Figure 5. Forest Plot with ORs on Overall Cancer Risk Associated with MMP2 -1306 C>T Gene Polymorphism (TT vs CC; Homozygous Model)
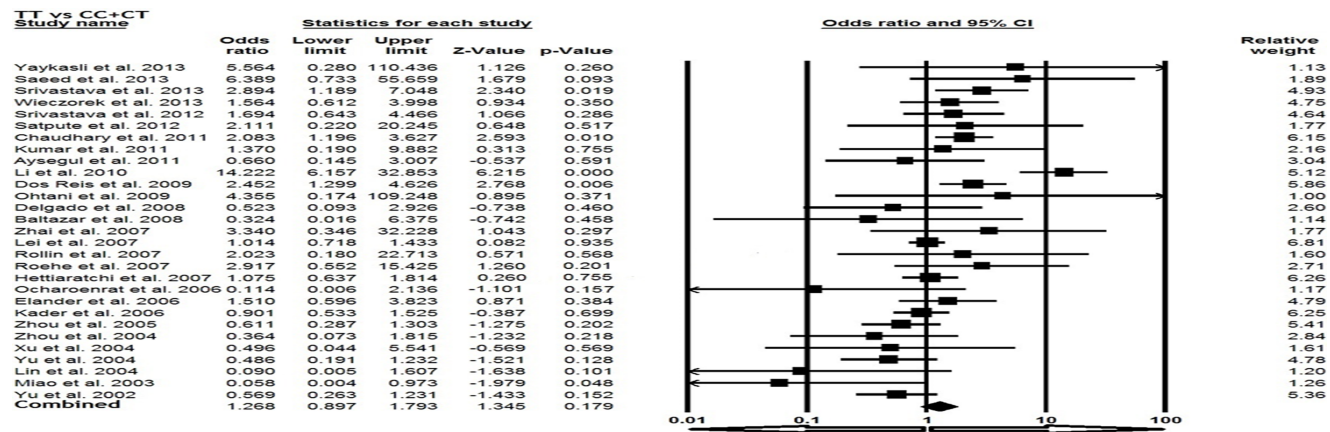

Figure 6. Forest Plot with ORs on Overall Cancer Risk Associated with MMP2 -1306 C>T Gene Polymorphism (TT vs CC+CT; Recessive Model)

two genetic models, heterozygous (CT vs $\mathrm{CC}: \mathrm{p}=0.002$; $\mathrm{OR}=0.758,95 \% \mathrm{CI}=0.637$ to $0.902 ;$ Figure 2$)$ and dominant model $(\mathrm{TT}+\mathrm{CT}$ vs $\mathrm{CC}: \mathrm{p}=0.032 ; \mathrm{OR}=0.816$,
$95 \% \mathrm{CI}=0.678$ to 0.982 ; Figure 3 ). However, allelic ( $\mathrm{T}$ vs $\mathrm{C}: \mathrm{p}=0.169 ; \mathrm{OR}=0.882,95 \% \mathrm{CI}=0.738$ to 1.055 ; Figure 4), homozygous (TT vs CC: $\mathrm{p}=0.358$; $\mathrm{OR}=1.185$, 
$95 \% \mathrm{CI}=0.825$ to 1.700 ; Figure 5 ) and recessive (TT vs $\mathrm{CC}+\mathrm{CT}: \mathrm{p}=0.179 ; \mathrm{OR}=1.268,95 \% \mathrm{CI}=0.897$ to 1.793 ; Figure 6) models did not show any increased or decreased risk of cancer.

\section{Discussion}

Cancer remains the most lethal disease worldwide, despite improvements in diagnostic and therapeutic techniques. It has been widely accepted that host genetic factors including genetic polymorphism, had garnered interest with regard to the study of the carcinogenesis. Microenvironment of tumor cells composed of numerous interdependent cell types, including fibroblast, endothelial and lymphatic cells; bone marrow derived cells and embedded with extracellular matrix (ECM). ECM of tumor has a unique composition and recognized as a major regulator of carcinogenesis (Hanahan and Weinberg, 2011). Disruption to such control mechanisms deregulates and disorganizes the ECM, leading to abnormal behaviors of cells residing in the niche and ultimately failure of organ homeostasis and function, permitting invasion into surrounding connective tissues, entry and exit from blood vessels, and metastasis to distant organs (Cox and Erler, 2011). MMPs are able to degrade virtually all ECM components and viewed as essential for tumor progression (Van Kempen et al., 2006). Expression of MMP2 is elevated in carcinomas in association with low differentiation grade and accelerated tumor progression (Vihinen and Kahari, 2002). Having known the important roles of MMPs in carcinogenesis, it is reasonable to speculate that host genomic polymorphism of MMP2 gene may affect the tumor occurrence. Recently, genetic variants of the MMP2 -1306 C > T gene polymorphism and its role in the etiology of several cancers have been studied extensively, but the results are inconclusive. As it is known that, individual studies with a small sample size may not have enough statistical power to detect a small risk factor. Our main focus was to estimate the more precise results to understand the contribution of MMP2 -1306 C>T gene polymorphism in overall cancer risk. Therefore, we performed the current meta-analysis to appraise whether MMP2 -1306 C>T gene polymorphism could have an impact on susceptibility to overall cancer.

This meta-analysis was based on the accumulation of all eligible data to analyze overall cancer susceptibility. The associations for the allele contrast, dominant and recessive model of MMP2 -1306 C>T were examined. We found that the MMP2 -1306 C $>$ T polymorphism were associated with a significantly reduced risk in heterozygous and dominant genetic models. The same trend of associations was also reported in meta-analysis of digestive and lung cancer as well as in metastasis of cancer ( $\mathrm{Li}$ et al., $\mathrm{Hu}$ et al., 2013; Liu et al., 2012). However, a recent metaanalysis suggests that MMP-2 C735T and C1306T polymorphisms influence susceptibility to lung cancer in Asians (Guo et al., 2012). The results of another metaanalysis suggest that MMP-2 -1306C $>$ T polymorphism is not associated with breast cancer susceptibility, although the association among Latin-Americans in the dominant model was found significant (Yang et al., 2014). MMP2
-1306 disrupt sp1 binding site and a previous study has demonstrated that a reduction in Sp1 DNA binding activity or phosphorylation by nonsteroidal anti-inflammatory drugs suppresses MMP2 expression (Pan et al., 2002). This observation clearly recommend that absence of the Sp1 sequence in the MMP2 gene would produce a lower level of MMP2 protein in individuals carrying -1306 T allele than those carrying the $\mathrm{C}$ allele. Reduced expression would be expected to be associated with a reduced risk of cancer. An animal study also shown that lower expression level of MMP2 is associated with reduced risk of tumor formation (Bergers et al., 2000; Itoh et al., 1998). MMPs are not always involved in development of cancer, they have also shown anti-tumor effects, as illustrated by the inhibiting effects on angiogenesis (Martin and Matrisian, 2007). However, cancer etiology is polygenic and role of different MMP polymorphisms in the risk of developing cancer is diverse. Hence, a single genetic variant is usually insufficient to predict risk of this complex disease.

Despite the current findings, our results have some limitations. Heterogeneity is an important issue when interpreting the results of meta-analysis. In present study we found inter-study heterogeneity. The source of heterogeneity may arise from many aspects, such as the region of study, the sample size the case and the control group, clinical characteristic of different tumor, and the genotyping method. Due to the limited number of studies, subgroup analysis was not performed and this study was based on unadjusted estimates, while a more precise analysis could be performed if individual data were available.

In spite of this, our current study has some advantage. Publication bias is a well-known problem that was not detected by funnel plot and Egger linear regression in the present meta-analysis indicating that the results are statistically robust. In this study we used explicit criteria for a study's inclusion and performed strict data extraction and analysis to make satisfactory and reliable conclusion.

In conclusion, a meta-analysis is an important tool of statistical data-analysis and pools both statistically significant and non-significant data from individual studies and suggests a precise and absolute conclusion. The overall results of this meta-analysis suggested that MMP2 -1306 C>T gene polymorphism is associated with decreased cancer risk. In the present study we only analyzed the MMP2 -1306 C>T variant, without considering the interaction between several other SNPs. In our future study, we will try to further explore the other pertinent interactions to facilitate the discovery of cancer development. In addition to the targeted research to further clarify a potential role of MMP $2-1306 \mathrm{C}>\mathrm{T}$ gene variant in cancer risk, future well designed large-scale studies with the consideration of gene-gene and gene-environment interactions should be warranted to evaluate the possible association.

\section{Acknowledgements}

We sincerely acknowledge the software program related support for statistical analysis provided by the Institute of Life Sciences (Bhubaneswar, India). 


\section{References}

Ayşegül B, Veysi GH, Muzaffer M, et al (2011). Is a single nucleotide polymorphism a risk factor for lung cancer in the matrix metalloproteinase-2 promoter? Mol Biol Rep, 38, 1469-74.

Baltazar-Rodriguez LM, Anaya-Ventura A, Andrade-Soto M, et al (2008). Polymorphism in the matrix metalloproteinase-2 gene promoter is associated with cervical neoplasm risk in Mexican women. Biochem Genet, 46, 137-144.

Bergers G, Brekken R, Mcmahon G, et al (2000). Matrix metalloproteinase- 9 triggers the angiogenic switch during carcinogenesis. Nature Cell Biol, 2, 737-744.

Bjorklund M, Koivunen E (2005). Gelatinase-mediated migration and invasion of cancer cells. Biochim Biophys Acta, 1755, 37-69.

Bonomi P (2002). Matrix metalloproteinases and matrix metalloproteinase inhibitors in lung cancer. Semin Oncol, 29, 78-86.

Burton PR, Hansell AL, Fortier I, et al (2009). Size matters: just how big is BIG? Quantifying realistic sample size requirements for human genome epidemiology. Int $J$ Epidemiol, 38, 263-73.

Chaudhary AK, Pandya S, Mehrotra R, et al (2011). Role of functional polymorphism of matrix metalloproteinase-2 $(-1306 \mathrm{C} / \mathrm{T}$ and $-168 \mathrm{G} / \mathrm{T})$ and MMP-9 $(-1562 \mathrm{C} / \mathrm{T})$ promoter in oral submucous fibrosis and head and neck squamous cell carcinoma in an Indian population. Biomarkers, 16, 577-86.

Cohn LD, Becker BJ (2003). How meta-analysis increases statistical power. Psychol Methods, 3, 243-53.

Cox TR, Erler JT (2011). Remodeling and homeostasis of the extracellular matrix: Implications for fibrotic diseases and cancer. Dis Model Mech, 4, 165-78.

Curran S, Murray GI (1999). Matrix metallproteinases in tumor invasion and metastasis. J Pathol, 189, 300-8.

Delgado-Enciso I, Cepeda-Lopez FR, Monrroy-Guizar EA, et al (2008). Matrix metalloproteinase-2 promoter polymorphism is associated with breast cancer in a Mexican population. Gynecol Obstet Invest, 65, 68-72.

DerSimonian R, Laird N (1986). Meta-analysis in clinical trials. Control Clin Trials, 7, 177-188.

Deryugina EI, Quigley JP (2006). Matrix metalloproteinases and tumor metastasis. Cancer Metastasis Rev, 25, 9-34.

Dos Reis ST, Pontes J Jr, Villanova FE, et al (2009). Genetic polymorphisms of matrix metalloproteinases: susceptibility and prognostic implications for prostate cancer. J Urol, 181, 2320-5.

Egger M, Davey Smith G, Schneider M, Minder C (1997). Bias in meta-analysis detected by a simple, graphical test. $B M J$, 7109, 629-34.

Elander N, Soderkvist P, Fransén K (2006). Matrix metalloproteinase (MMP) $-1,-2,-3$ and -9 promoter polymorphisms in colorectal cancer. Anticancer Res, 26, 791-5.

Guo X, Wang J, Zhang L, et al (2012). Quantitative assessment of the effects of MMP-2 polymorphisms on lung carcinoma risk. Asian Pac J Cancer Prev, 13, 2853-6

Hanahan D, Weinberg RA (2011). Hallmarks of cancer: the next generation. Cell, 144, 646-674.

Hettiaratchi A, Hawkins NJ, McKenzie G, et al (2007). The collagenase-1 (MMP-1) gene promoter polymorphism $1607 / 2 \mathrm{G}$ is associated with favourable prognosis in patients with colorectal cancer. Br J Cancer, 96, 783-792.

Higgins JP, Thompson SG, Deeks JJ, Altman DG (2003). Measuring inconsistency in meta-analyses. $B M J, \mathbf{7 4 1 4}$, 557-60.

Hu C, Wang J, Xu Y, et al (2013). Current evidence on the relationship between five polymorphisms in the matrix metalloproteinases (MMP) gene and lung cancer risk: a meta-analysis. Gene, 517, 65-71.

Itoh T, Tanioka M, Yoshida H, et al (1998). Reduced angiogenesis and tumor progression in gelatinase A-deficient mice. Cancer Res, 58, 1048-51.

Jemal A, Bray F, Center MM, et al (2011). Global cancer statistics. CA Cancer J Clin, 61, 69-90.

Kader AK, Shao L, Dinney CP, et al (2006). Matrix metalloproteinase polymorphisms and bladder cancer risk. Cancer Res, 66, 11644-8.

Kang SH, Brown DA, Kitajima I, et al (1996). Binding and functional effects of transcriptional factor $\mathrm{Sp} 1$ on the murine interleukin-6 promotor. $J$ Biol Chem, 271, 7330-5.

Kumar R, Malik N, Tungaria A, Kawal P (2011). Matrix metalloproteinase-2 gene polymorphism is not associated with increased glioblastoma multiforme susceptibility: an Indian institutional experience. Neurol India, 59, 236-240.

Lebeau A, Muller-Aufdemkamp C, Allmacher C, et al (2004). Cellular protein and mRNA expression patterns of matrix metalloproteinases- 2, -3 and -9 in human breast cancer: correlation with tumour growth. J Mol Histol, 35, 443-455.

Lei H, Hemminki K, Altieri A, et al (2007). Promoter polymorphisms in matrix metalloproteinases and their inhibitors: few associations with breast cancer susceptibility and progression. Breast Cancer Res Treat, 103, 61-69.

Li X, Qu L, Zhong Y, et al (2013). Association between promoters polymorphisms of matrix metalloproteinases and risk of digestive cancers: a meta-analysis.J Cancer Res Clin Oncol, 139, 1433-47.

Li Y, Sun DL, Duan YN, et al (2010). Association of functional polymorphisms in MMPs genes with gastric cardia adenocarcinoma and esophageal squamous cell carcinoma in high incidence region of North China. Mol Biol Rep, 37, 197-205.

Lichtenstein P, Holm NV, Verkasalo PK, et al (2000). Environmental and heritable factors in the causation of cancer--analyses of cohorts of twins from Sweden, Denmark, and Finland. N Engl J Med, 343, 78-85.

Lin SC, Lo SS, Liu CJ, et al (2004). Functional genotype in matrix metalloproteinases-2 promoter is a risk factor for oral carcinogenesis. J Oral Pathol Med, 33, 405-9.

Liu D, Guo H, Li Y, et al (2012). Association between polymorphisms in the promoter regions of matrix metalloproteinases (MMPs) and risk of cancer metastasis: a meta-analysis. PLoS One, 7, 31251 .

Mandal RK, Yadav SS, Panda AK (2013). Meta-analysis on the association of nucleotide excision repair gene XPD A751C variant and cancer susceptibility among Indian population. Mol Biol Rep. (Epub ahead of print)

Mantel N, Haenszel W (1959). Statistical aspects of the analysis of data from retrospective studies of disease. J Natl Cancer Inst, 4, 719-48.

Martin MD, Matrisian LM (2007). The other side of MMPs: protective roles in tumor progression. Cancer Metastasis Rev, 26, 717-24.

Miao X, Yu C, Tan W, et al (2003). A functional polymorphism in the matrix metalloproteinase- 2 gene promoter $(-1306 \mathrm{C} / \mathrm{T})$ is associated with risk of development but not metastasis of gastric cardia adenocarcinoma. Cancer Res, 63, 3987-90.

Nabeshima K, Inoue T, Shimao Y, Sameshima T (2002). Matrix metalloproteinases in tumor invasion: role for cell migration. Pathol Int, 52, 255-64.

O-Charoenrat P, Khantapura P (2006). The role of genetic polymorphisms in the promoters of the matrix metalloproteinase- 2 and tissue inhibitor of metalloproteinase-2 genes in head and neck cancer. Oral 
Shafiul Haque et al Oncol, 42, 257-67.

Ohtani H, Maeda N, Murawaki Y (2009). Functional polymorphisms in the promoter regions of matrix metalloproteinase-2, -3, -7, -9 and TNF-alpha genes, and the risk of colorectal neoplasms in Japanese. Yonago Acta Medica, 52, 47-56.

Pan MR, Hung WC (2002). Nonsteroidal anti-inflammatory drugs inhibit matrix metalloproteinase-2 via suppression of the ERK/ Sp1-mediated transcription. Proc Natl Acad Sci USA, 277, 32775-380.

Pharoah PD, Dunning AM, Ponder BA, Easton DF (2004). Association studies for finding cancer-susceptibility genetic variants. Nat Rev Cancer, 4, 850-60.

Price SJ, Greaves DR, Watkins H (2001). Identification of novel, functional genetic variants in the human matrix metalloproteinase-2 gene: role of $\mathrm{Sp} 1$ in allele-specific transcriptional regulation. $J$ Biol Chem, 276, 7549-58.

Qin H, Sun Y, Benveniste EN (1999). The transcription factors Sp1, Sp3, and AP-2 are required for constitutive matrix metalloproteinase- 2 gene expression in astroglioma cells. $J$ Biol Chem, 274, 29130-7.

Roehe AV, Frazzon AP, Agnes G, et al (2007). Detection of polymorphisms in the promoters of matrix metalloproteinases 2 and 9 genes in breast cancer in South Brazil: preliminary results. Breast Cancer Res Treat, 102, 123-4.

Rollin J, Régina S, Vourc'h P, et al (2007). Influence of MMP-2 and MMP-9 promoter polymorphisms on gene expression and clinical outcome of non-small cell lung cancer. Lung Cancer, 56, 273-80.

Saeed HM, Alanazi MS, Parine NR, et al (2013). Matrix metalloproteinase-2 (-1306 c>t) promoter polymorphism and risk of colorectal cancer in the saudi population. Asian Pac J Cancer Prev, 14, 6025-30.

Satpute SP, Hazarey VK, Ganvir SM (2012). Estimation of matrix metalloproteinases-2 promoter polymorphism as a risk factor for oral carcinogenesis in Indian population. Scientific reports, 1, 1-4.

Shalaby MA, Nounou HA, Alanazi MS, et al (2014). Associations between single nucleotide polymorphisms of COX-2 and MMP-2 genes and colorectal cancer susceptibility in the Saudi population. Asian Pac J Cancer Prev, 15, 4989-4994.

Srivastava P, Kapoor R, Mittal RD (2013). Association of single nucleotide polymorphisms in promoter of matrix metalloproteinase-2, 8 genes with bladder cancer risk in Northern India. Urol Oncol, 31, 247-54.

Srivastava P,Lone TA, Kapoor R, Mittal RD (2012). Association of promoter polymorphisms in MMP2 and TIMP2 with prostate cancer susceptibility in North India. Arch Med Res, 43, 117-24.

Sternlicht MD, Werb Z (1999). Matrix metalloproteinase. In Kreis $\mathrm{T}$ and Vale $\mathrm{R}$ (eds) guidebook to the extracellular matrix, anchor and adhesion proteins. Oxford University Press, New York, 503-603.

van Kempen LC, de Visser KE, Coussens LM (2006). Inflammation, proteases and cancer. Eur J Cancer, 42, 728-34.

Vihinen P, Kahari VM (2002). Matrix metalloproteinases in cancer: prognostic markers and therapeutic targets. Int $J$ Cancer, 99, 157-166.

Wagenaar-Miller RA, Gorden L, Matrisian LM (2004). Matrix metalloproteinases in colorectal cancer: is it worth talking about? Cancer Metastasis Rev, 23, 119-135.

Wieczorek E, Reszka E, Jablonowski Z, et al (2013). Genetic polymorphisms in matrix metalloproteinases (MMPs) and tissue inhibitors of MPs (TIMPs), and bladder cancer susceptibility. BJU Int, 112, 1207-14.

Woolf B (1955). On estimating the relation between blood group and disease. Ann Hum Genet, 19, 251-3.

Wu R, Li B (1999). A multiplicative-epistatic model for analyzing interspecific differences in outcrossing species. Biometrics, 2, 355-65.

Xu E, Lai M, Lv B, et al (1999). A single nucleotide polymorphism in the matrix metalloproteinase-2 promoter is associated with colorectal cancer. Biochem Biophys Res Commun, 324, 999-1003.

Yang L, Li N, Wang S, et al (2014). Lack of association between the matrix metalloproteinase- $2-1306 \mathrm{C}>\mathrm{T}$ polymorphism and breast cancer susceptibility: a meta-analysis. Asian Pac J Cancer Prev, 15, 4823-7

Yaykasli KO, Kayikci MA, Yamak N, et al (2014). Polymorphisms in MMP-2 and TIMP-2 in Turkish patients with prostate cancer. Turk J Med Sci, 44.

Yu C, Pan K, Xing D, et al (2002). Correlation between a single nucleotide polymorphism in the matrix metalloproteinase-2 promoter and risk of lung cancer. Cancer Res, 62, 6430-33.

Yu C, Zhou Y, Miao X, et al (2004). Functional haplotypes in the promoter of matrix metalloproteinase-2 predict risk of the occurrence and metastasis of esophageal cancer. Cancer Res, 64, 7622-8.

Zhai Y, Qiu W, Dong XJ, et al (2007). Functional polymorphisms in the promoters of MMP-1, MMP-2, MMP-3, MMP-9, MMP-12 and MMP-13 are not associated with hepatocellular carcinoma risk. Gut, 56, 445-7.

Zhou Y, Yu C, Miao X, et al (2004). Substantial reduction in risk of breast cancer associated with genetic polymorphisms in the promoters of the matrix metalloproteinase- 2 and tissue inhibitor of metalloproteinase-2 genes. Carcinogenesis, 25, 399-404.

Zhou Y, Yu C, Miao X, et al (2005). Functional haplotypes in the promoter of matrix metalloproteinase- 2 and lung cancer susceptibility. Carcinogenesis, 26, 1117-21. 